\title{
PROBLEMS AND ASPECTS OF PRESENT-DAY RESIDUE ANALYSIS
}

\author{
H. FREHSE* \\ Bayer AG, Pflanzenschutz, Anwendungstechnik, Biologische Forschung, \\ Institut für Rückstandsanalytik, Leverkusen, GFR
}

\begin{abstract}
A general review is given of the analytical, statistical, toxicological and 'philosophical' role of pesticide residue analysis within the evaluation of food and environmental problems. The presentation is intended as an updating of the situation which was prevalent and described 3 years ago, as well as an outlook on future trends and developments.
\end{abstract}

It has been amply defined what residues $\operatorname{are}^{1 \mathbf{b}, \mathbf{d} ; 2}$ but no one has yet defined what the tasks of residue analysis are. For residue analysis now deals also with air, eggshells and arctic snow. The definition of residues introduced for foods can, of course, be applied on principle to all substrates of the environment. But nevertheless I should like to make a distinction between 'residue analysis' and 'environmental analysis', if only for the reason that workers engaged in environmental analysis usually prefer to speak of contaminants (cf. ref. 3) or pollutants (cf. ref. 51) rather than residues. You are all familiar with diagrams of the kind presented in Figure 1. I regard the tasks of residue analysis as being suitably outlined by the right-hand half of the diagram, i.e. in direct association with the application of pesticides. The basic studies linked with the development of new pesticides and which are essential for registration of the latter are also incorporated in this sphere of tasks. There are of course instances where residue analysis and environmental analysis converge or even overlap, particularly in analytical methodology. Both also have a duty in common, beyond their purely scientific functions, namely responsibility. Along with the widely cited 'protection of the consumer' (this being understood to mean protection against 'poison' and 'hazards of chemistry') there is also a need for psychological protection (against spread of uncertainty). In this respect, many analysts could and in fact ought to display greater involvement-for example, by explaining in clearer terms what they are devising. In all the work they perform today, they need the cooperation of their neighbouring disciplines. This Congress brings together, at international level, all whose concern this is: environmentalists, legislators, official crop protection experts, residue analysts, residue chemists and toxicologists (in alphabetical order).

* English translation by J. Edwards. 


\section{H. FREHSE}

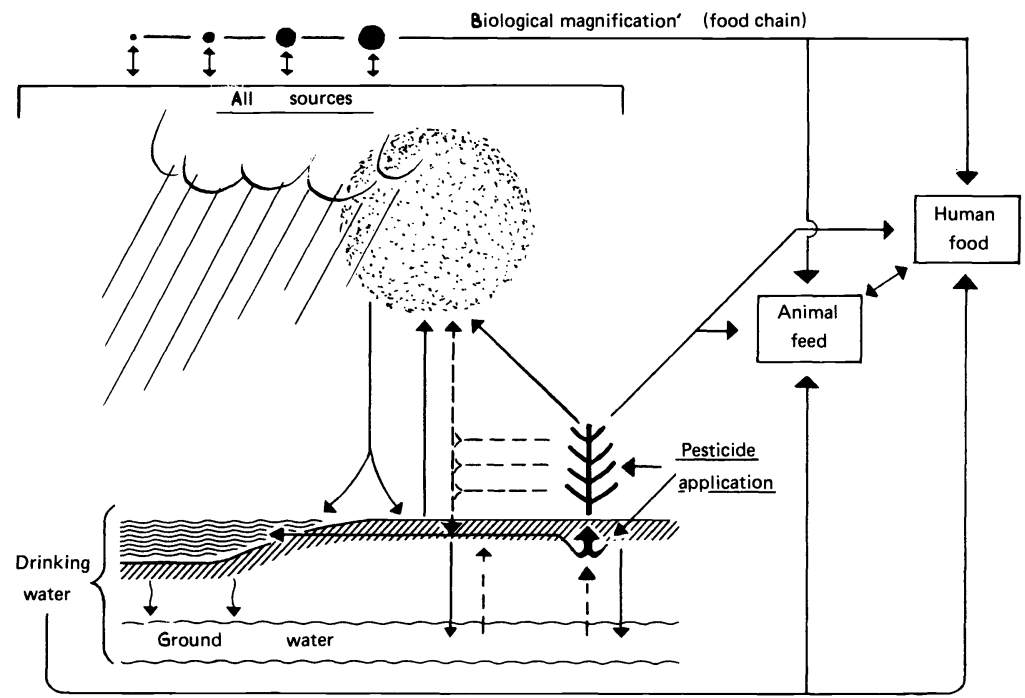

Figure 1. Schematic diagram of the possible ultimate residual and environmental fate of a pesticide

Therefore, my contribution, unlike the paper I presented in 1971 in Tel Aviv $^{4}$, will not be of a predominantly technical nature. It aims at outlining selected problems of a more general kind, in the hope that the papers and discussions at this Congress will help in drawing closer to solutions of them. The scientific or technological development of residue analysis will be dependent, in a hardly foreseeable manner, upon the pragmatic demands of environment protection and of legislation. However, the problems of the present day make it necessary to put at least aspects in the place of prognoses. In this connection, I should like to place the emphasis on residues in the conventional sense of the term, i.e. in relation to their direct potential impact on man, and not on the biochemical or physical (photoalteration ${ }^{5}$, transportation $^{6,7}$, distribution $^{8}$ )mechanisms, by means of which they are formed ${ }^{9-11}$ or in some cases are globally distributed ${ }^{12-14}$. After all, the undue eagerness with which, for many years, hundreds of laboratories, and speakers as well, have been devoting themselves to the environmental fate of but a few organochlorine pesticides now seldom has an inspiring effect; on the contrary, it has resulted in creating the irreparable impression among the general public that the behaviour of this group of compounds is representative of that of pesticides generally.

\section{ON THE SITUATION OF RESIDUE ANALYSIS}

Two bestsellers published in the USA have decisively influenced the nature of present-day residue analysis: Public Law 83-518 (Section 408 of 
which is better known as The Miller Bill or The Pesticide Chemicals Amendment), of 1954, and Silent Spring, of 1962. The one resulted in the present-day 'tolerance' concept and the establishment of permitted amounts of residues in foodstuffs and feeds; the other was instrumental in triggering off, although on a basis not generally recognized as authoritative, a world-wide discussion on residues and their significance for the environment. I wish to summarize briefly the outcome of this development, although in doing so I cannot avoid touching on problems which to some will appear obvious.

The analysts were able to lower the detection limits of their methods by several powers of 10 . They have developed methods by means of which groups of residues can be determined with a limited measure of specificity. But the more 'sensitive' the methods became, the more numerous were the environmental problems that arose, and non-pesticides interfered all the more with the analysis; thus, the PCBs and the PCTs ${ }^{15}$, among others, found their way into the literature on pesticides, before DDT was recognized as a possible additional source for $\mathrm{PCBs}^{16}$.

We know now that (1) pesticides can undergo chemical alteration, under natural conditions, to an extent that was not foreseeable; among the metabolites formed are also those one can hardly expect to find in free form but only as conjugates ${ }^{17}$ which confront the analyst with exceptional problems; (2) it is possible for plants, soil and secondary substrates (air, surface water, organisms of the food chain) to contain, at any time during greatly varying periods after the application of pesticides, a metabolite mixture of constantly changing composition ${ }^{18}$, the diversity of which can be recognized only by using isotope-labelled compounds; thus, the term 'terminal residues' emerged, yet it still cannot be defined ${ }^{19}$; (3) transformation and degradation of pesticides may exhibit considerable differences also in the kinetic sense; consequently 'persistence' (cf. P 3) and 'accumulation' which originally were related to the parent compounds assumed a new yet likewise undefined significance.

The era in which residues were identified with organosolubles has perhaps ended, but we are still without an answer to the question whether watersoluble metabolites are residues. Analysts and residue chemists are filled with growing uneasiness by having no alternative but to work selectively, namely with only those compounds which are extractable.

In the toxicology of pesticides ${ }^{20}$ acute toxicity, which justifiably had been withdrawn as a measure of the significance of residues, assumed renewed importance in residue analysis in association with the re-entry problem ${ }^{21,22}$. The expansion of experimental techniques in the area of long-term studies meanwhile made it possible for the WHO Expert Committee on Pesticide Residues $^{23}$ to establish about 80 maximum acceptable daily intake (a.d.i.) values $^{1 \mathrm{e}, \mathrm{f} ; 24}$ on which food legislation can now be based world-wide. Unfortunately, this meritorious achievement embraces only a small proportion of all the pesticides that are in use. It cannot be denied, either, that in the past toxicology concentrated too much on warning against risks instead of placing greater emphasis on a more accurate determination of 'risk'25. Residue analysis has also been affected by this, because it lacks conclusive guidelines urgently needed for the interpretation of its results.

We have not been told in which situations or below which limit metabolites 


\section{H. FREHSE}

may be neglected. A metabolite which accounts for $5 \%$ of the total residue naturally would have to be $\mathbf{2 0 0}$ times more toxic than the parent compound to raise the toxicity of the residue by a power of 10 . As far as I am aware, a terminal residue with such properties is not known.

We have not been told whether and to what extent conjugates may be considered as residues, and the fact that diligent analysts are able to determine them is alone inconclusive evidence. We also wish to see an end to the dispute over safety factors ${ }^{26}$ with which results of animal experiments can be converted for application to foods ${ }^{27,28}$. Either the 'factor of 100 ' (actually it is a divisor) is scientifically tenable, and one should then acknowledge it, or else it is not, so that one should then seek another (or several others) and acknowledge that.

In many countries the legislative bodies have also made advances. They have established an increasing number of tolerances and safety intervals and, it is gratifying to note, have departed from the zero tolerance concept ${ }^{29 *}$. However, the impression is gained that, despite this progress, pace is not always kept with the development of new pesticides or the emergence of fresh scientific knowledge. Endeavours to harmonize the laws within large political or economic communities have begun but the zeal with which some countries defend their own tolerances against these endeavours has also disclosed the misfortune of the national legislations and, hence, the question whether large-area solutions have a chance of one day being set above national regulations or even superseding them. There are reasons for viewing this with scepticism, since international groups and sub-groups also compete with one another in this respect. The FAO/WHO Codex Alimentarius Committee on Pesticide Residues (CCPR $)^{30}$ particularly sees itself confronted with these problems (refs. 1d, 2, 31; see also P 279, P 280, P 283). Thus, the meritorious evaluations of the FAO/WHO Joint Meeting on Pesticide Residues (JMPR) ${ }^{24}$ and particularly of the FAO Working Party of Experts on Pesticide Residues (see also P 278), which prepare the scientific foundations for international tolerances, are placed in question. Yet it is almost a humanitarian problem that the different people are compelled to live with different tolerances, provided this is not justified by greatly differing eating habits ${ }^{27}$. The field of residue analysis has little chance of developing generally valid analytical methods as long as it has to satisfy requirements which differ from one country to another. Major advances in food control could have long since been achieved if only it had been possible to use uniform methods which provide indications, on a yes/no basis, of tolerances being exceeded.

What is more, the official crop protection organizations failed to make it clear to consumers and judges that tolerances are not limit values between the ranges 'harmless' and 'dangerous' (see also ref. 32). Publications on food analyses, in which percentages of analysed samples containing residues above and below the tolerance level are communicated to the public, also make

\footnotetext{
* Recently, the established term 'tolerance' is no longer used throughout for denoting the permitted maximum concentration of a residue in a given substrate. For example, the CCPR has replaced it by the term 'maximum residue limit'2. The term 'practical residue limit' is used when a residue results from circumstances not designed to protect the food (commodity) in question against pest attack (ref. 2; cf. ref. 1b).
} 
hardly any comment on this question*. To construe tolerances with their seeming accuracy as constituting threshold values in this sense would, however, be tantamount to overlooking both biological and analytical reality. For this reason, the 'official' analyst also finds himself faced with a still unresolved problem when he comes across residues of an amount close to the tolerance level and it is left to his discretion to decide whether he should declare them as exceeding the tolerance.

I wish to deal somewhat more closely with problems associated with the establishment of tolerances and with residue analysis in general.

\section{PROBLEMS ASSOCIATED WITH THE ESTABLISHMENT OF TOLERANCES}

The concept of the establishment of tolerances (cf. P 282, P 473) is not clear; or, should it be clear to the legislators, it has not been made clear to residue analysts, who, after all, have to procure the fundamental data for the legislators.

When a tolerance leans too heavily on a statistically inadequate amount of residue data, then it must inevitably be considered more as a reflection of the average residue situation. On the other hand, tolerances can also be construed as the legally permitted absolute maximum limit or concentration. It was in this sense that the JMPR ${ }^{1 \mathrm{~b}, \mathrm{~d}}$ and the $\mathrm{CCPR}^{2}$, for example, defined a tolerance. However, it is not admissible to establish tolerances in accordance with the first concept and to enforce them in accordance with the second one. The purpose of tolerances is to enable a control to be made of what is termed 'good agricultural practice' ${ }^{\mathbf{b}, \mathrm{d} ; 2}$. In its nature, this control function is retrospective. It extends from the analytical result to the foregoing application of a product, covering a number of very complex processes all subject to possible errors.

A situation $X$ that is required to be controlled can be demonstrated in a schematic model (Figure 2). In this model it is assumed that all the shown steps involved in the formation and determination of residues follow a normal distribution. Assigned to each step is a relative standard deviation (coefficient of variation) $S$, being $\pm 20 \%$ for the application, $\pm 30 \%$ for the differences from year to year (i.e. essentially for the climatically conditioned fluctuations), etc., with allowance additionally being made for a $10 \%$ loss during clean-up. It will be readily appreciated that these estimates are of a cautious nature rather than unrealistic. Applying the error-propagation law, and not taking into account the loss during clean-up, they correspond to a total relative standard deviation $S_{1}$ of $\pm 39 \%$. For this model, it holds that the analytical results may vary between the values $0.4 X$ and $1.8 X$ (for the three field steps alone, the corresponding limits are at $0.5 X$ and $1.7 X$ ). If, instead of the given onefold standard deviations which embrace only $68 \%$ of all possible cases, the twofold standard deviations $(2 S)$ are taken as the basis, i.e. at application $\pm 40 \%$, etc., the analytical results may range between $0.1 X$

\footnotetext{
* The meaningfulness of such statistics is obviously of a very limited nature in those instances where it is not also precisely stated how many compounds (residues) have been included in the investigation.
} 


\section{H. FREHSE}

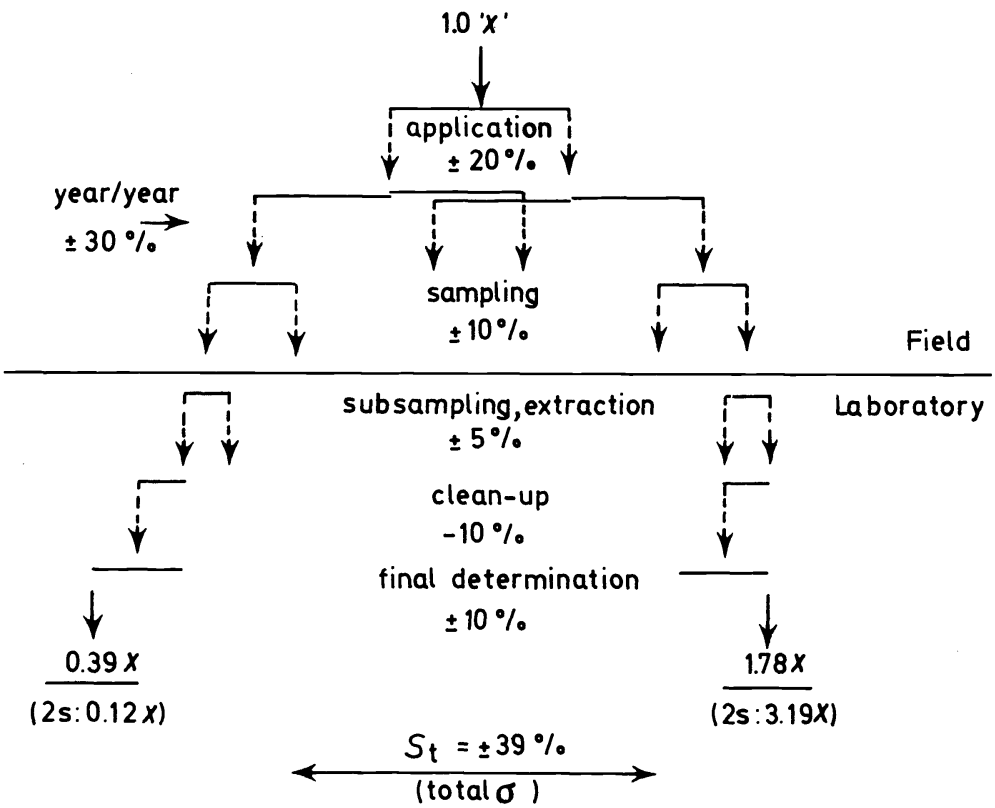

Figure 2. Schematic diagram of the consecutive ranges of variations within the major steps involved in the formation and determination of residues

and 3.2 $X^{*}$. A tolerance to be established for the 'case $X^{\prime}$ ' must allow in some form or other for the upper limit. Either it itself must be furnished with a 'tolerance' or it must be set at an appropriately high level, yet below what is toxicologically feasible (= permissible level; cf. Figure 3). In either case it is essential that the uncertainties remain restricted to a statistical minimum to be agreed upon. But the greater the demands on statistical significance, the less possible it will be to keep the required number of field trials and analyses within tenable bounds.

As long as it has not been proved that the processes involved in the formation of a residue follow a normal distribution, it cannot be ruled out that they do not. For this case it must be assumed that the measured values derive from a continuous, non-parametric distribution, and the following statement holds (cf. ref. 33): When it is required that a proportion of $g \%$ of the total population be smaller in value than the maximum value of the sample $\left(x_{[N]}\right)$ and that this statement is made with a confidence of $(1-\alpha) \%$, a sample size will be needed such as given in Table 1 for some examples. In other words, only when, for example, 299 items are analysed can it be stated with a probability of $95 \%$ that $99 \%$ of all possible items will exhibit a smaller amount of residue than the highest amount of residue found. It is obvious that with a 'normal' sample size of 10 to 20 , only a slight degree of confidence is attainable.

* The given limits are not minimum or maximum values in the absolute sense but have the character of accumulated maximum errors, i.e. they themselves are again subject to a deviation, although it is greatly narrowed. 
Table 1. Number of samples required from distribution-free populations. The following equation applies: $P\left\{P\left(x<x_{[N]}\right) \geqslant g\right\}=1-\alpha$, where $\alpha$ is the probability of error. Data obtained from ref. 33

\begin{tabular}{ccccc}
\hline & $g \rightarrow$ & & & \\
$(1-\alpha) \%$ & $80 \%$ & $90 \%$ & $95 \%$ & $99 \%$ \\
\hline 90 & 11 & 22 & 45 & 230 \\
95 & 14 & 29 & 59 & 299 \\
99 & 21 & 44 & 90 & 459 \\
\hline
\end{tabular}

Some examples which lay no claim to completeness or representativeness will be given to demonstrate the possible ranges of variation of some of the steps shown in Figure 2. I urgently invite everyone who is able to contribute further or better data on these aspects to publish them.

\section{Deposit formation (cf. ref. 34)}

Five organophosphorus insecticides (BAY 80 833, fenitrothion, parathion, parathion-methyl, trichloronat) and their oxons were each sprayed adjacently on 80 lettuce plants in exactly dosed and equal amounts $(0.15 \mathrm{~kg} \text { a.i. } / \mathrm{ha})^{35,36}$. Three hours after the spray application, samples were taken and each sample was analysed in duplicate. From the 20 analyses, a mean deposit value of $M=1.76 \pm 0.50$ p.p.m. $(= \pm 28 \%)$ was obtained; the extreme values were 1.06 and 2.48 p.p.m., corresponding to $0.6 \mathrm{M}$ and $1.4 \mathrm{M}$. This example holds for uniform application technique and spray concentration. If, however, the spray concentration of the formulation is altered, but the amount of active ingredient applied per unit area remains constant, the differences in the deposit formation may be considerable. Experiments conducted over several years on apples using three different, commercially formulated active ingredients (dichlofluanid, oxythioquinox, parathion) indicated that with a tenfold concentration the amounts of residues are, on average, two-thirds higher than under normal conditions and that with a twentyfold concentration they are twice as high. Moreover, the dispersion of the individual values substantially increases with increasing spray concentration ${ }^{37}$.

\section{Soil sampling ${ }^{38}$ (see also refs 39, P 25)}

Three separate operators each took nine samples of soil $\left(3 \times 25,50\right.$ and 75 cores; 1 core $\left./ 5 \mathrm{~m}^{2}\right)$. The same programme was carried out on a chalky loam soil and on a high-organic peat soil, and included three insecticides (aldrin, dieldrin, DDT) at different residue levels (0.1 to 10 p.p.m.). Duplicate sub-samples were taken from each sample and each sub-sample was analysed in duplicate. Increasing the number of cores reduced the variation between samples, the gain in precision being significant between 25 and 50 cores but not from 50 to 75 cores. The sampling errors were not affected by operators, by the soil type, by the nature of the insecticide or by the concentration and homogeneity of the residue (once-incorporated versus an old often-cultivated residue). The relative standard deviations were:

$$
\begin{aligned}
\text { operator }+ \text { sampling }+ \text { subsampling }+ \text { determination } & = \pm 7.6 \% \\
\text { sampling }+ \text { subsampling }+ \text { determination } & = \pm 7.6 \% \\
\text { subsampling }+ \text { determination } & = \pm 4.8 \% \\
\text { determination } & = \pm 3.8 \%
\end{aligned}
$$

In other words, in this experiment the operators contributed nothing to the total variation. Since the 'determination' coefficient was half the total coefficient, the steps in the analytical method contributed only one-quarter of the variation of the whole procedure. The equipment, reagents and techniques were common to one laboratory, and so the above relative standard deviations represent 'repeatability' estimates; one should expect the 'reproducibility' of the operations to be significantly greater.

\section{Extraction}

Weathered residues of ${ }^{32} \mathrm{P}$-labelled fenthion were extracted by three different procedures from a uniform, very carefully chopped and mixed sample (comprising three sub-samples for each 


\section{H. FREHSE}

Table 2. Recovery of trichloronat and its oxon from bananas (results from 1 operator). Calculated from data recorded by Möllhoff ${ }^{4}$

\begin{tabular}{|c|c|c|c|c|c|c|c|}
\hline & \multirow{2}{*}{$\begin{array}{l}\text { p.p.m. } \\
\text { added }\end{array}$} & \multicolumn{4}{|c|}{$\begin{array}{l}\text { Number of } \\
\text { analyses* }\end{array}$} & \multicolumn{2}{|c|}{$\begin{array}{c}\text { Mean recovery (\%) } \\
\pm \text { relative standard deviation } \dagger\end{array}$} \\
\hline & & I & II & III & $\mathbf{V}$ & trichloronat & -oxon \\
\hline Peel & $\begin{array}{l}0.02 \\
0.05\end{array}$ & 2 & 4 & 5 & $\begin{array}{l}5 \\
4\end{array}$ & $\begin{array}{l}91 \pm 2.4 \% \\
91 \pm 7.5 \%\end{array}$ & $\begin{array}{l}82 \pm 5.8 \% \\
76 \pm 9.5 \%\end{array}$ \\
\hline Pulp & $\begin{array}{l}0.02 \\
0.05\end{array}$ & 2 & 4 & 5 & $\begin{array}{l}5 \\
4\end{array}$ & $\begin{array}{l}91 \pm 4.0 \% \\
96 \pm 3.2 \%\end{array}$ & $\begin{array}{l}79 \pm 8.7 \% \\
77 \pm 15 \%\end{array}$ \\
\hline
\end{tabular}

* Roman figures: month 1968.

$\dagger$ Estimated according to Dean and Dixon ${ }^{42}$

procedure) of beet leaves. The chloroform-soluble residues in each of the parallel samples deviated between 10 and $30 \%$ from the mean ${ }^{40}$. Recovery determinations made after in vitro fortification of parent compound prior to the extraction are usually subject to smaller deviations. Table 2 gives the means for 10 trials each in a total series of 80 trials conducted on bananas with trichloronat and its oxon ${ }^{36,41}$. With one exception, the relative standard deviations were less than $10 \%$, even in those cases where the determinations were made at three different times. All analyses were performed by one and the same operator.

Quantitative determination by $G L C^{43}$

In an experimental analysis run over a period of $17 \mathrm{~h}$, in which determinations of disulfoton $(0.03 \mathrm{ng})$, ethion $(0.03 \mathrm{ng})$ and thionazin (zinophos) $(0.035 \mathrm{ng})$ were each repeated 45 times, the evaluation of the peak areas with an integrator revealed relative standard deviations of between 7 and $9.5 \%$. In this experiment an automatic injector and a thermionic detector were used.

Directly linked with the dilemma of establishing tolerances is the problem of working out statistically sound sampling plans. Kruysse has recently discussed this question (see also P 279) and has suggested, for the purposes of the CCPR, a sequential sampling plan $^{44}$ (see also ref. 45 ) in which three items are sampled from a batch (lot). After analysing the first item, one of the following decisions is taken: the lot is accepted if the residue concentration $x \leqslant$ tolerance $L_{\mathrm{m}}$; the lot is rejected if $x>L_{\mathrm{r}}\left[L_{\mathrm{r}}>L_{\mathrm{m}}\right]$; the analysis is repeated with the second item if $x$ lies between the two limit values, and the same decision procedure is then followed as with the first item. After analysing the third item, the lot is accepted if $x \leqslant L_{\mathrm{m}}$, or the lot is rejected if $x>L_{\mathrm{m}}$.

This plan, however, presupposes the existence of an as yet imaginary 'tolerance-tolerance' $\left(L_{\mathrm{r}}\right)$ of which Kruysse says: 'it has to be set, for the time being, in each individual case or according to a formula which will have to be worked out at a level corresponding as closely as possible with the actionable levels which already actually exist at sampling, although they may not very often be published as such'. Legislators, analysts and statisticians must jointly strive towards bringing about a statistical moderation of this problem.

It should not be overlooked, either, that the so precise tolerances relate to imprecisely defined material. Of course, they usually relate to the raw agricultural commodity, but this does not always have anything to do with the protection of the consumer for whom the non-edible portions attach no significance, but, nevertheless, may be of substantial proportions, as shown by Table 
Table 3. Non-edible portions of selected food commodities (\%) (range and average). Source of data: Souci, Fachmann and Kraut ${ }^{46}$

\begin{tabular}{lrrlll}
\hline Grapes & $4-10$ & 6 & Bananas & $14-43$ & 32 \\
Peaches & $2-15$ & 8 & Head lettuce & $20-46$ & 33 \\
Cherries & $6-18$ & 11 & Lemons & $20-53$ & 36 \\
Carrots & $10-30$ & 17 & Cauliflower & $25-55$ & 38 \\
Spinach & $10-34$ & 22 & Broccoli & $23-55$ & 39 \\
Savoy cabbage & $18-40$ & 28 & Pineapple & $20-83$ & 44 \\
Oranges & $20-41$ & 28 & Watermelons & $40-71$ & 56 \\
\hline
\end{tabular}

3. It is known that analysts tend to handle this situation pragmatically in three different ways: (1) the total commodity is analysed and the result is related to it; (2) only the edible portions are analysed and the result is related to them; (3) only the edible portions are analysed and the result is related to the total commodity.

When it is considered that residue values are calculated on a weight basis and that in many kinds of vegetables, for example, the major proportions of the residues may be present in the practically 'weightless', non-edible outer plant parts, it will be realized how little the comparability of the corresponding results may be, this being very clearly demonstrated in Table 4 . The same considerations apply also to academic studies, say on the degradation dynamics of residues.

Table 4. Residue $=1.0$ p.p.m. in the total commodity

\begin{tabular}{ccccc}
\hline $\begin{array}{c}\text { Edible } \\
\text { portion, \% }\end{array}$ & 20 & \multicolumn{2}{c}{$\begin{array}{c}\text { Percentage of total residue in the edible portion } \\
40\end{array}$} & 60 \\
\hline 30 & 0.67 & 1.3 & 2.0 & 80 \\
50 & 0.40 & 0.80 & 1.2 & 2.7 \\
70 & 0.29 & 0.57 & 0.86 & 1.6 \\
90 & 0.22 & 0.44 & 0.67 & 1.1 \\
& \multicolumn{4}{c}{ Residues (p.p.m.) in the edible portion } \\
\hline
\end{tabular}

\section{CHOICE AND VALIDATION OF RESIDUE ANALYTICAL METHODS}

In future it will be necessary for the efforts undertaken in the field of residue analysis to be concentrated more on such aims as may be of further assistance also to other analysts or to legislators or to food control authorities. For example, greater restraint should be exercised in the development of more and more new methods for the same compounds*. It would be much more beneficial if the already existing methods, provided they are basically good, were to be further improved upon and to be validated, and an exchange of

* In the Analytical Abstracts, 11 methods for 2,4-D, 12 methods for carbaryl, 16 methods for malathion and 41 methods for DDT were, for example, reported within only 3 years (Vols. 20-25, 1971-1973). These methods all relate to the determination of residues either in plant or animal material or in soil or in water. 


\section{H. FREHSE}

experience gained with them were to be pursued (see also P 26, P 27, P 43). It will be realized how very necessary this is when it is considered that the 'special' methods, i.e. those developed for individual pesticides and their residues, must continue to be used along with multiresidue methods for some considerable time to come because they serve different purposes. Attention has been repeatedly drawn to this ${ }^{1 \mathrm{~d}, 4,47,48-1971 \mathrm{RA}}$. At present, not only are reliable special methods wanting for a number of pesticides; the multimethods, too, have not yet been developed to such a degree that the special ones could be dispensed with. One cannot help feeling alarmed at the fact that groups of experts (e.g. within AOAC, CCPR, FAO or IUPAC) have to occupy themselves with the task of selecting from the overabundance of methods those which seem useful for a certain purpose.

In this connection one should also reflect on the significance of collaborative studies and ask oneself whether the enormous analytical potential which is blocked by them could not be put to better use. In view of the very large number of pesticides and the substrates in which they may be contained, the chances of such studies keeping pace with current needs are very slight, unless the joint efforts are concentrated on the development of multimethods of really large capacity.

Egan points out that a new feature, which in part has replaced the collaborative studies, is the development of practical guidance manuals ${ }^{49}$. These and other selected methods could meet with valuable support by being validated by experienced laboratories. Smart, Hill and Roughan ${ }^{50}$ compared, for example, published and unpublished (but likely to be widely used) methods for the determination of organochlorine residues in plant and animal foods, and found that there were no gross discrepancies in the results obtained, although for certain foodstuffs and in certain situations some methods appeared preferable to others.

Restraint is also called for in what has become an exorbitant bid for increasingly greater analytical 'sensitivity'. It is seemingly becoming fashionable to consider a residue method to be all the more superior the smaller are the concentrations it is capable of determining. However, it is easy to prove that too many such methods are based not upon adequate quantifications, e.g. by recovery experiments, in these extremely low ranges, but rather upon inadmissible extrapolations (e.g. from peak areas obtained with pure compound). Analysts who proceed in this way secure for themselves an unjustified advantage over other colleagues who treat these things with greater conscientiousness. There is a growing number of publications reporting p.p.t. concentrations in water (e.g. refs. 14, 52, 53, 54, 55) or ng amounts per cubic metre of air (e.g. refs. 14, 56). But this does not only concern the pesticide analysts. We now also know, for example, that the air over the North-east Atlantic contains, on average, $1.7 \mathrm{ng}$ of chloroform per cubic metre ${ }^{57}$. We should, however, try to find our way back to a realistic assessment of p.p.b.s and p.p.t.s*. Assuming someone possesses 1 billion $\left(10^{9}\right)$ dollars and spends it at the rate of 1000 dollars a day, it would take him 2740 years, not counting the interest, until

* In accordance with a recommendation of the IUPAC Pesticides Section ${ }^{48-1970 \text { RA }}$ terms of the type $\mathrm{mg} / \mathrm{kg}, \mathrm{mg} / \mathrm{l}, \mathrm{ng} / \mathrm{kg}$, etc., are to be preferred to p.p.m. (parts per $10^{6}$ ), p.p.b. (parts per $10^{9}$ ) or p.p.t. (parts per $10^{12}$ ), to avoid possible confusion. A 'psychological' problem nevertheless remains, because for the non-expert $1 \mathrm{ng} / \mathrm{kg}$ is also still 1 part of 'something'; he does not realize that this is 10 powers of 10 less than $1 \%$. 
he is down to the very last dollar, in other words 1 p.p.b. of his original wealth. In a body of water containing 1 p.p.t. of a pesticide having a molecular weight of 360 , each pesticide molecule is surrounded by 20 trillion $\left(20 \times 10^{12}\right)$ water molecules. Unfortunately, these figures alone, though very imposing, do not indicate whether this water is drinkable. When we take a look at some of the tolerances for DDT discussed by the CCPR ${ }^{31}$, even though they are presented in an unconventional manner (Table 5), then the dispute over

Table 5. Examples of CCPR tolerances for DDT $\left(1974^{31}\right)$

\begin{tabular}{|c|c|c|c|c|c|c|}
\hline \multirow{2}{*}{$\begin{array}{l}\text { Commodity } \\
\text { Eggs }\end{array}$} & \multicolumn{6}{|c|}{ Molecules $/ 100 \mathrm{~g}$ commodity } \\
\hline & 85 & 000 & 000 & 000 & 000 & $000^{a}$ \\
\hline Strawberries, root vegetables & 170 & 000 & 000 & 000 & 000 & 000 \\
\hline Milk and milk products (fat basis) & 213 & 000 & 000 & 000 & 000 & $000^{a}$ \\
\hline Cherries, citrus, plums & 597 & 000 & 000 & 000 & 000 & 000 \\
\hline $\begin{array}{l}\text { Apples, apricots, pears, peaches, } \\
\text { small fruits; vegetables }\end{array}$ & 1195 & 000 & 000 & 000 & 000 & 000 \\
\hline 1 p.p.t. $\left(1: 10^{12}\right)$ & & & 170 & 000 & 000 & 000 \\
\hline
\end{tabular}

a 'Practical residue limit'.

whether a tolerance should be 1.0 or 1.25 p.p.m. seems somewhat strange; likewise the question as to what is gained by forcing the limit of determination down to 1 p.p.t. We are, of course, just as incapable of proving the absence of a compound as the toxicologists are of proving scientifically that no deleterious effect has taken place, i.e. of proving the negative. What we need is some acceptable premise for establishing some minimum level of exposure to a substance that can be unequivocally accepted as the equivalent of zero ${ }^{25}$ (see also ref. 58). If this should make it necessary to penetrate into the p.p.t. range or still farther 'downwards', then and only then will the elaborate and analytically risky exercise of developing such highly 'sensitive' methods be worthwhile. I would go so far as to demand that residue results should only be published when their significance can be interpreted; in other words, can be related in a normal case to a permitted maximum limit. With this demand I do not wish either to belittle the value of analytical work connected with the environment or to offend anyone, but rather to stress the need for intensifying efforts directed towards the establishment of internationally agreed standards for pesticide residues. We cannot hope to make any real progress in analysis until we have succeeded in adjusting the disparity between the abundance of available data and the lack of possibilities for interpreting them. This holds for all areas of residue analysis, whether the analysis relates to the evaluation of field research, to routine regulatory screening or to monitoring the environment.

The field of residue analysis is often confronted with the demand to work out or specify standard methods for the analysis of residues of a pesticide or groups of pesticides for regulatory or referee purposes ${ }^{1 a, b, d}$. This demand is rightly opposed by the analysts. Experiences with standard methods in other areas of analysis cannot be readily applied to pesticide residue analysis. 


\section{H. FREHSE}

Both the JMPR and the Commission on Pesticide Residue Analysis of the IUPAC Pesticides Section have expressed their opposition to such demands ${ }^{1 \mathrm{~d} . e ; 48-1973 \mathrm{RA}}$. Apart from scientific misgivings which are expressed here, it also remains to be considered whether the responsibility of the analyst should be added to in such cases where standardized methods are desired, by issuing regulations stating how he has to discharge this responsibility. I wish to substantiate this by presenting some figures taken from a highly informative Australian study ${ }^{59}$. In collaboration with the Netherlands and the UK, three samples of malathion-treated wheat from bulk storage were analysed by 11 laboratories using four different established methods. Table 6 provides a summary of the results obtained for one of the three samples,

Table 6. Determination of malathion in wheat (11 laboratories, 22 analysts, 4 methods). Standard deviations and total error calculated by the author

\begin{tabular}{|c|c|c|c|c|}
\hline \multicolumn{2}{|c|}{ Total variability } & \multicolumn{3}{|c|}{ Variability of each method } \\
\hline mean $\pm s$ & range & method & mean $\pm s$ & 'total error'a \\
\hline 6.85 p.p.m. $\pm 27 \%$ & 4.0-15.4 p.p.m. & $\begin{array}{l}\text { A } \\
\text { B }\end{array}$ & 6.3 p.p.m. $\pm 12 \%$ & $31 \%$ \\
\hline \multirow{3}{*}{\multicolumn{2}{|c|}{$\begin{array}{l}116 \text { determinations } \\
18 \text { results }>8.0 \text { p.p.m. }\end{array}$}} & $\mathrm{C}$ & 7.5 p.p.m. $\pm 35 \%$ & $85 \%$ \\
\hline & & & 7.0 p.p.m. $\pm 20 \%$ & $41 \%$ \\
\hline & & \multicolumn{3}{|c|}{$\begin{array}{l}\text { A is Laboratories' own method } \\
\mathrm{C} \text { is a Panel method }\end{array}$} \\
\hline
\end{tabular}

a Calculated from total mean. $s$ denotes relative standard deviation.

which contained residues just below the Codex tolerance of 8.0 p.p.m. For this sample, 116 analytical results are available (between 26 and 34 from each of the 4 methods). The experiments have revealed that results vary widely between laboratories, irrespective of methods employed. Experience with a particular method reduces the variation considerably. Different operators using the same method in the same laboratory can report results which differ from the mean by $50 \%$. Also, it was obvious that the variations from laboratory to laboratory and method to method are sufficiently large to cause serious problems in administering tolerance limits. There is a high risk that consignments of treated wheat could be rejected even when the apparently true residue level is less than half the tolerance limit. Another striking feature of these results is that a panel method exhibited the highest total error*.

* McFarren, Lishka and Parker ${ }^{60}$ have suggested using the term 'total error' $\left(E_{V}\right)$ as the criterion for judging the acceptability of analytical methods (especially for the purpose of collaborative studies), and have defined this term as the percentage ratio of ( $2 s+$ [absolute value of] mean error) to the 'true value'. When $E_{t}>50 \%$, the method shall be regarded as 'unacceptable'; if $E_{\mathrm{t}} \leqslant 25 \%$, it will be considered 'excellent'. Using this criterion for evaluating 336 results from 32 collaborative studies of the AOAC with organochlorine residues ${ }^{61}$, then only about $30 \%$ of the data would have been judged 'excellent', although only $10 \%$ would have been 'unacceptable' (see ref. 62 for an evaluation of PCB/DDT studies). In a Swiss study with rapeseed oil, in which nine laboratories participated ${ }^{63}$, the results for lindane $(0.125$ p.p.m.), dieldrin ( 0.375 p.p.m.) and DDT (+DDE + DDD; 0.75 p.p.m.) would have been 'acceptable' on the basis of this rating, whereas the results for $\mathrm{HCB}(0.25$ p.p.m.) would have been 'unacceptable'. 


\section{SPECIAL PROBLEMS OF ANALYTICAL TECHNIQUES}

The extensive programme of this Congress promises to provide a comprehensive survey of developments in analytical techniques during the last few years. Few colleagues still find time to do this in summarized reviews (e.g. refs. $29,64,65,66$ ). I should like to mention a few particular aspects which seem worthwhile discussing.

Gel chromatography and gel filtration ${ }^{67-69,} \mathrm{P} 14$, (high-pressure) liquid chromatography in general ${ }^{70,71}$ and the combined GC/MS technique had not been sufficiently perfected for them to secure wider usage in routine residue analysis. Liquid chromatography will not and cannot replace gas chromatography ${ }^{72}$, but there are so many samples which are not volatile that it will certainly see a strong growth rate for a number of years. Separation and purification for direct mass spectrometric analysis can be elaborate and often give poor yields. GC/MS couplings have largely moderated this problem (and probably LC/MS couplings ${ }^{73}$ will soon be able to achieve the same); they now also permit the use of stable isotopes like ${ }^{13} \mathrm{C}$ or ${ }^{15} \mathrm{~N}$ in metabolite research ${ }^{74}$. Sweep co-distillation is another technique I wish to mention here. Following the first successful automation experiments ${ }^{75}$, P11, one would now look forward to a systematic study being conducted showing which pesticides and which metabolites can be distilled from which substrates by means of this technique. Other automation experiments, it is regretted to say, have had little success as yet with respect to extraction and clean-up, procedures in which automation would be really beneficial. Within the category of multi-residue methods, group methods by means of which chemically related residues can be determined assume a special position. Organochlorine compounds, phenyl-urea compounds ${ }^{76}$ and triazine compounds ${ }^{77}$ are known examples of the successful endeavours in this area. The prospects of methods being developed for joint determination of organophosphates have so far been slight because of the very large number of compounds in question. Little success has so far been achieved also for $N$-methyl carbamates, partly owing to thermal breakdown in $\mathrm{GLC}^{78}$.

The known methods are based on derivatization techniques (suitable for electron capture detection) involving hydrolytic cleavage and subsequent reaction with the liberated amine (e.g. ref. 79) or phenol (e.g. refs. 80-82). According to our experiences ${ }^{83,84}$, the transesterification technique of Moye ${ }^{85}$ is most useful but it requires an efficient thermionic $\mathrm{N}$-detector to determine the $O$-methyl- $N$-methyl carbamate formed as the result of transesterification in the injection port. Hydroxylated carbamates can also be directly extracted from the water phase and determined by this technique ${ }^{86}$.

The still largely uninvestigated area of hydrolysis techniques for conjugates and the analysis of aglycons will have to be discussed at length. Systematic studies of the nature of the glycoside or amino acid components in relation to the plant species probably constitute a prerequisite for arriving at generally applicable working techniques.

Interesting analytical and, at the same time, legislative questions arise when it is not possible to differentiate between parent compound and primary metabolites, because the possibly still present pesticide is converted into a metabolite during the extraction or clean-up procedure. Prototypical of this 


\section{H. FREHSE}

pattern are the systemic fungicides of the benomyl type which, for routine purposes, are seemingly analysable only in the form of the carbendazim $\left(^{B H C}, \mathrm{MBC}\right)^{70,87,88}$ (see also refs. 89, 90).

In this connection, the fluorescence methods, which had receded into the background, have again become of interest ${ }^{91,92}$. Generally, the fluorescence technique is not particularly suitable for residue analysis because of the rigorous clean-up required. On the other hand, the new fluorometric derivatization (or 'fluorigenic labelling') methods offer promising possibilities ${ }^{\mathbf{9 3}}$.

In most laboratories analytical results touching on the lower borderline of what is analytically feasible are still interpreted in an arbitrary manner. The terms 'limit of determination' and 'limit of detection' have been defined also for the purposes of residue analysis ${ }^{1 \mathrm{~d}}$ but what is still wanting is a simple and, above all, generally agreed procedure which, in the light of blanks, instrument noise, limits of error and recoveries, permits analytical results to be assigned to these defined terms. This problem is of considerable importance for the enforcement of negligible residues ${ }^{1 e}$ and application bans. A satisfactory solution could also help in preventing irresponsible advertsing of 'residue-free' foods.

\section{QUESTIONS AND SUGGESTIONS AND OLD PROBLEMS}

Although we naturally expect to have every opportunity of discussing innovations in analytical techniques at this Congress, we should not overlook the fact that there are still old problems and questions familiar to almost everyone but nevertheless still waiting to be solved. And again, they concern not only residue chemists and analysts but also toxicologists and legislators. I should like to list a few more of these problems which have not yet been mentioned, and also to put forward some suggestions (see also ref. 4).

Still largely unresolved is the old problem of recoveries, i.e. the question as to what extent in vitro fortifications prior to extraction can be a measure of the actual efficiency of a method for determining 'in vivo residues'.

We need far more systematic data on: the influence of climatic factors on residue formation; the influence of post-harvest factors on the fate of residues; residues in food moving in international commerce; residues in the ready-toeat total diet; residues in foods of animal origin, which stem from residues in feeds.

Some of these data could help one to become better acquainted with the 'dilution factors' which contribute towards a continual reduction of toxicity (Figure 3) from the commercial product down to the food on the table (see also refs. 94-96). As long as we do not have sufficient data, the powers of 10 given in the illustration must remain very generalized estimates. If better figures were available, more could be done to reassure the food consumer by pointing out to him, particularly in view of the a.d.i. values, that the actual daily intake ${ }^{97}$ is substantially lower than the potential or 'theoretical'97 daily intake which is calculated from residues at tolerance level ${ }^{1 \mathrm{a}-\mathrm{d}, 2,31,98}$. Unfortunately, there is an astounding disproportion between the number of publications on residue methods and the number of those on residue values*.

* Residue data should always include a statement expressing whether they have been calculated for $100 \%$ recovery or not, provided the quality of the method does not make this unnecessary. 


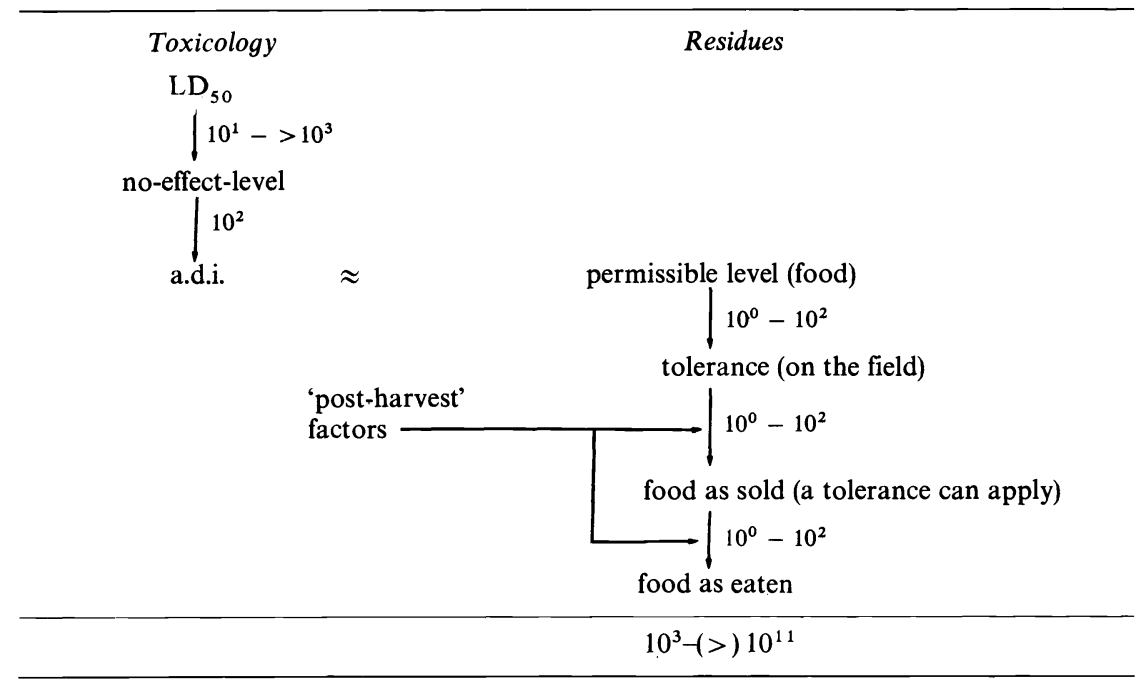

Figure 3. Toxicology-to-residue 'dilution factors'

Methods for the quantitative extraction of residues from soil and the relationships between non-extractability and biological availability ought to be systematically investigated (cf. ref. 99). In this connection, the term 'persistence ${ }^{, 14,100}$ ought to be revised and above all defined, perhaps as suggested by Robinson ${ }^{101}$, according to whom a compound should be termed as persistent when at a given time the ratio of lapsed time to biological half-life is less than 0.01 . It must also take into account the possible carryover of persisting residues from soil into following crops. Residues which are not absorbed into plants should be considered separately from persistent compounds potentially capable of forming residues in edible plant parts. Studies with isotopelabelled pesticides on plants likewise confirm that a portion of the applied radioactivity may not be extractable and therefore not identifiable. We should reach agreement that unextractables may be disregarded provided it can be demonstrated that they are also physiologically unavailable in mammals.

Many multimethods need extending to include significant metabolites, and should not be regarded as valid until this condition has been fulfilled. Most of these methods only provide information on which compounds can be determined. Systematic studies are wanting to indicate what compounds can not be determined and what other compounds (other pesticides, physiological compounds, synthetic 'non-pesticides') might interfere (such as undertaken for the first time by Bowman, Beroza and Hill ${ }^{102}$ ). If sufficient information were available indicating what compounds are not determined, I would refer to this as a 'negative confirmation technique' and regard it as a genuine expansion of the multimethods. A most useful service would also be rendered if someone were prepared to review the different confirmation or 
'positive identification' techniques, likewise the numerous derivatization techniques, insofar as they have been used with success in support of the multimethods.

Which criteria, apart from cholinesterase inhibition for organophosphates and carbamates, could be used for assessing the toxicological significance of metabolites? What is the toxicological significance of conjugates? Are there basically any toxicological differences between conjugates with glycoses and conjugates with amino acids ${ }^{103}$ ? A possibility would be to define transformation and degradation products of pesticides as 'residue' as long as these products are non-physiological. Unfortunately, this is opposed by the fact that nature is also capable of producing toxic substances.

Studies on the 'behaviour of pesticides in water' are frequently also a precondition for the registration of pesticides. But there is no agreement on an experimental technique to be used for this purpose, which would enable the results to be compared. The micro-ecosystem described by Metcalf ${ }^{104-106}$ (see also P 103, P 150) is without doubt an ideal academic model but it hardly lends itself to routine studies.

Tolerances should be expressed to only one significant digit ${ }^{1 \mathrm{c}}$, and this should be done only in units of 1,2 and $5^{1 \mathrm{f}}$. Finer differentiations are unrealistic. Exceptional cases where tolerances exceed, say, 10 p.p.m. could be discussed $^{1 \mathrm{ff}}$. Furthermore, the reference factors of tolerances should be made clearer. The first reference factor is the compound. That means tolerances should, on principle, relate only to the parent compound, or it must be stated which metabolites should be included in the analysis. The decision on this point should not be left to the analyst. Tolerances should not, however, be established for metabolites. The second reference factor is the food commodity. Here tolerances should relate only to clearly defined crops or commodities and not to undefined omnibus terms like 'soft fruits', 'vegetables', etc.; otherwise it is impossible to arrive at comparable residue data ${ }^{1 \mathrm{f}}$. Furthermore, generally valid lists should be compiled of those crops which can be related with respect to residue data; such lists are in use, for example, in the $\mathrm{USA}^{107}$ and in the Federal Republic of Germany ${ }^{108}$.

\section{IUPAC, SECTION ON PESTICIDES}

Within the Applied Chemistry Division of the IUPAC, a Section on Pesticides has been in existence since 1959 (present Chairman: Dr D. C. Abbott, UK). The Section has two Commissions, which were established in 1965, namely the Commission on Terminal Pesticide Residues (Chairman: Dr K. R. Hill, USA) and the Commission on Pesticide Residue Analysis (Chairman: Dr H. Frehse). Their objectives are so closely linked with the general and special problems of pesticide residues that I should like to outline them briefly.

While the Section concerns itself generally with matters of policy, international liaison, membership, publications, sponsorship by IUPAC and arrangements of Symposia and Congresses on Pesticide Chemistry, the detailed work is carried out through the Commission and was, in years past, largely based on problem areas as indicated by the requirements of the annual 
FAO/WHO-JMPR. The work of the Section has always been closely associated with the deliberations of this Joint Meeting. However, there is also close cooperation with other international bodies, including the CCPR, OECD, EEC and the Joint FAO/IAEA Division. The requirements of the JMPR are carefully considered, and advice on availability of procedures suitable for regulatory purposes is given to the Joint Meeting and also to the CCPR. Other assignments arise directly from members' interests or known 'problem areas' of wide concern. The TR-Commission is concerned with the nature of terminal residues and with the metabolic pathways by which degradation occurs. The RA-Commission works in a similar manner to, and in conjunction with, the TR-Commission. While the TR-Commission specifies the nature of the residues to be sought, the RA-Commission discourses on the suitability of various analytical procedures for the required purpose; it has been particularly concerned with multi-residue procedures. Commission members evaluate available information, stimulate work in progress and attempt to initiate work in neglected areas of importance.

The results of the deliberations of the Section and the two Commissions are published in brief in the $J A O A C$, and at length in the IUPAC's own organs ${ }^{48}$.

The Titular and Associate Members of the Section and the Commissions are recognized experts in their particular field. Therefore, the Section provides a unique forum for government, academic and industrial scientists to meet, as individuals rather than representatives of interests, to further their common aims and stimulate progress where unanswered problems remain. The Section can, and is prepared to, provide independent advice in the areas of residue chemistry and residue analysis to any institution interested in matters of such a nature, and it would appreciate being consulted in this respect. As it is not the intention of the Section to expand its activities beyond the field of pesticides, the RA-Commission might become more closely involved in environmental analysis problems in the future.

\section{CLOSING COMMENTS}

As long as chemical crop protection is a reality, so also are pesticides as a possible component of the environment and our food. I spoke at the beginning about the responsibility of pesticide scientists to the public, a responsibility which arises out of the continuing spread of uncertainty. But residue analysis also has to suffer from spread of uncertainty, where it actually should be spreading confidence. I have attempted to outline this and how it could be reduced. Residue analysis can be more than just, so to speak, a factory producing figures for the public and the legislators. It is also highly unlikely that a connection exists between the future of mankind and the number of peaks we find. It ought to be possible to substantiate this assumption through cooperation, devoid of mutual prejudices, between the experts of governments, universities and industry.

I am indebted to the organizers of this Congress for having given me an opportunity to present here some aspects of the complex of problems associated with residue analysis. I feel most honoured by the invitation to speak on this subject, and it has been a great pleasure for me to accept it. 


\section{H. FREHSE}

\section{CHEMICAL NAMES OF PESTICIDES MENTIONED IN TEXT}

aldrin

BAY 80833

DDT

dichlofluanid

dieldrin

disulfoton

ethion

fenitrothion

fenthion

malathion

oxythioquinox

parathion

parathion-methyl

trichloronat

'zinophos' (thionazin) 1,2,3,4,10,10-hexachloro-1,4,4a,5,8,8a-hexahydro-exo-1,4-endo5,8-dimethanonaphthalene

3,4-dichlorophenyl methyl methylphosphonothionate

1,1,1-trichloro-2,2-di(4-chlorophenyl) ethane

$N$-[(dichlorofluoromethyl)-thio]- $N^{\prime} N^{\prime}-$

dimethyl- $N$-phenylsulphamide

1,2,3,4,10,10-hexachloro-6,7-epoxy-

1,4,4a,5,6,7,8,8a-octahydro-exo-1,4-endo-

5,8-dimethanonaphthalene

diethyl $S$-[2-(ethylthio)ethyl] phosphorothiolothionate

tetraethyl $S S^{\prime}$-methylene bis-(phosphorothiolothionate)

dimethyl 3-methyl-4-nitrophenyl phosphorothionate

dimethyl 3-methyl-4-methylthiophenyl phosphorothionate

$S$-[1,2-di(ethoxycarbonyl)-ethyl] dimethyl

phosphorothiolothionate

5-methyl-2-oxo-1,3-dithiolo[4,5-b]quinoxaline

diethyl 4-nitrophenyl phosphorothionate

dimethyl 4-nitrophenyl phosphorothionate

ethyl 2,4,5-trichlorophenyl ethylphosphonothionate

diethyl 2-pyrazinyl phosphorothionate

\section{REFERENCES}

The cited papers were not selected from the viewpoint of providing a complete literature support of the thoughts set forth in this lecture, but merely to present some recent deliberations and research results of colleagues for further supplementing certain statements. The few references, cited in the text and marked with the letter $P$, relate to the respective papers as announced in the Final Programme (Fourth Circular) for the Congress*.

${ }^{1}$ Reports of the Joint Meetings of the FAO Working Party of Experts on Pesticide Residues and the WHO Expert Committee on Pesticide Residues:

(a) 1968: FAO Agric. Studies No. 78, Rome (1969); Wld Hlth Org. Techn. Rep. Ser. No. 417, Geneva (1969);

(b) 1969: FAO Agric. Studies No. 84, Rome (1970); Wld Hlth Org. Techn. Rep. Ser. No. 458; Geneva (1970);

(c) 1970: FAO Agric. Studies No. 87, Rome (1971); Wld Hlth Org. Techn. Rep. Ser. No. 474, Geneva (1971);

(d) 1971: FAO Agric. Studies No. 88, Rome (1972); Wld Hlth Org. Techn. Rep. Ser. No. 502, Geneva (1972);

(e) 1972: FAO Agric. Studies No. 90, Rome (1973); Wld Hlth Org. Techn. Rep. Ser. No. 525, Geneva (1973);

(f) 1973: FAO Agric. Studies No. 92, Rome (1974); Wld Hlth Org. Techn. Rep. Ser. No. 545, Geneva (1974).

${ }^{2}$ FAO/WHO, Report of the Sixth Session of the Codex Committee on Pesticide Residues, Alinorm 72/24 A (Febr. 1973).

${ }^{3}$ H. Egan, Proc. Nutr. Soc. 31, 23 (1972).

${ }^{4}$ H. Frehse, in A. S. Tahori (Ed.), Methods in Residue Analysis. Proc. 2 nd Int. Congr. Pest. Chem., Vol. IV, p 113. Gordon and Breach; New York (1971).

5 D. A. M. Watkins, Chem. Ind. 185 (1974).

6 F. Pooler, Jr., Nat. Tech. Inform. Serv. Com-72-10454 (1972); [Health Aspects of Pesticides 1973-2095].

7 P. R. Evans, Chem. Ind. 197 (1974).

${ }^{8}$ R. A. E. Galley, Chem. Ind. 179 (1974).

* P3 to be published in this journal; P11, P14, P26, P27, P43, P103, P150 to be published in Environ. Qual. Safety; P279, P473 to be published in Res. Rev. 


\section{PROBLEMS AND ASPECTS OF PRESENT-DAY RESIDUE ANALYSIS}

9 C. Wedemeyer, Univ. Washington Publ. Fish. New Ser. 5, 69 (1972); [Health Aspects of Pesticides 1973-2821].

10 M. Alexander, Biotechnol. Bioeng. 15, 611 (1973).

11 D. G. Crosby, Ann. Rev. Plant Physiol. 24, 467 (1973).

12 F. P. W. Winteringham, Israel J. Entomol. 6, 171 (1971).

13 R. L. Rudd, in W. W. Murdoch (Ed.), Environment, p 279. Sinauer; Stamford, Connecticut (1972).

14 C. A. Edwards, Persistent Pesticides in the Environment, 2nd. edn. CRC Press; Cleveland, Ohio (1973).

15 G. F. Fries and G. S. Marrow, J.A.O.A.C. 56, 1002 (1973).

16 T. H. Maugh II, Science 180, 578 (1973).

17 R. E. Menzer, Residue Rev. 48, 79 (1973).

18 R. C. Blinn, Int. J. Environ. Anal. Chem. 3, 33 (1973).

19 Frehse, H. in A. S. Tahori (Ed.), Pesticide Terminal Residues, p 9. Butterworths; London (1971).

${ }^{20}$ K. Kay, Environ. Res. 6, 202-243 (1973).

21 F. A. Gunther, W. E. Westlake, J. H. Barkley, W. Winterlin and L. Langbehn, Bull. Environ. Contam. Toxicol. 9, 243 (1973).

22 W. F. Serat, Arch. Environ. Contam. Toxicol. 1, 170 (1973).

${ }^{23}$ F. C. Lu, Residue Rev. 45, 81 (1973); WHO Chronicle, 27, 43 (1973).

24 D. Armstrong Lowe and A. R. Stiles, Bull. Wld Hlth Org. 49, 169 (1973).

25 L. Friedman, in G. H. Acheson (Ed.), Pharmacology and the Future of Man, Proc. 5th Int. Congr. Pharmacol., Vol. 2, p 30. Karger; Basel (1973).

26 C. S. Weil, Toxicol. Appl. Pharmacol. 21, 454 (1972).

27 P. H. Mollenhauer, Arch. Lebensmittelhyg. 23, 169 (1972).

28 F. Bär, Arch. Toxicol. 32, 51 (1974).

29 G. Zweig, in F. R. Blood (Ed.), Essays in Toxicology, Vol. 2, p 155. Academic Press; New York (1970).

30 F. C. Lu, WHO Chronicle, 27, 245 (1973).

31 FAO/WHO, Report of the Seventh Session of the Codex Committee on Pesticide Residues, Alinorm 74/24 (1974).

32 N. van Tiel, in F. Coulston and F. Korte (Eds.), Environmental Quality and Safety, Vol. I, p 180. Thieme/Academic Press; Stuttgart/New York (1972).

33 Documenta Geigy (K. Diem and C. Lentner), Wissenschaftliche Tabellen, 7, Aufl., p 128, Basel (1968).

${ }^{34}$ F. Hoerger and E. E. Kenaga, in F. Coulston and F. Korte (Eds.), Environmental Quality and Safety, Vol. I, p 9. Thieme/Academic Press; Stuttgart/New York (1972).

35 E. Möllhoff, Bayer AG, Pflanzenschutz, Anwendungstechnik, Biologische Forschung, Institut für Rückstandsanalytik, Leverkusen, unpublished (1967).

36 E. Möllhoff, Pflanzenschutz-Nachr. Bayer, 21, 331 (1968).

37 Bayer AG, Pflanzenschutz, Anwendungstechnik, Biologische Forschung, Leverkusen, unpublished.

38 K. E. Elgar, Woodstock Laboratory, Sittingbourne Research Centre, Shell Research Ltd., U.K., private communication (May 1974).

39 A. W. Taylor and H. L. Barrows, in A. S. Tahori (Ed.), Methods in Residue Analysis. Proc. 2nd Int. Congr. Pest. Chem., Vol. IV, p 439. Gordon and Breach: New York (1971).

40 H. Frehse and H. Niessen, Z. Anal. Chem. 192, 94 (1963).

41 E. Möllhoff, Bayer AG, Pflanzenschutz, Anwendungstechnik, Biologische Forschung, Institut für Rückstandsanalytik, Leverkusen, unpublished (1968).

42 R. B. Dean and W. J. Dixon, Anal. Chem. 23, 636 (1951).

43 W. Ebing, Dtsch. Lebensm.-Rdsch. 69, 39 (1973).

44 A. Kruysse, Codex Committee on Pesticide Residues, 7th Session, CX/PR 74/7 (Dec. 1973).

45 A. Kruysse, Codex Committee on Methods of Analysis and Sampling, CX/MAS 73/13-14 (March 1973).

46 S. W. Souci, W. Fachmann and H. Kraut, Die Zusammensetzung der Lebensmittel, Vol. II. Wiss. Verlagsgesellschaft; Stuttgart $(1962,1964,1969)$.

47 H. Frehse, Pflanzenschutz-Nachr. Bayer, 23, 196 (1970).

48 Reports of IUPAC Pesticides Section (S) and Commission (RA and TR) meetings: 1964/65: S Comptes Rendus XXIII Conf., p 237. London 1966/67: S Comptes Rendus XXIV Conf., p 173. London 


\section{H. FREHSE}

1966: RA J.A.O.A.C. 50, 1067 (1967)

TR J.A.O.A.C. 50, 1071 (1967)

1967: RA J.A.O.A.C. 51, 365 (1968); IUP AC Inf. Bull. 32, 81 (1968)

TR J.A.O.A.C. 51, 372 (1968); IUPAC Inf. Bull. 32, 81 (1968)

1968: $\quad \mathrm{S}$ (no report issued)

RA J.A.O.A.C. 52, 306 (1969); IUP AC Inf. Bull. 34, 43 (1969)

TR J.A.O.A.C. 52, 299 (1969); IUP AC Inf. Bull. 34, 35 (1969)

1969: S Comptes Rendus XXV Conf., p $166(1970)$

RA J.A.O.A.C. 53, 1004 (1970); Comptes Rendus XXV Conf., p. 196 (1970)

TR J.A.O.A.C. 53, 987 (1970); Comptes Rendus XXV Conf., p 168 (1970)

1970: S IUPAC Inf. Bull. 39, 54 (1971)

RA J.A.O.A.C. 54, 1332 (1971); IUP AC Inf. Bull. 40, 44 (1971)

TR J.A.O.A.C. 54, 1316 (1971); IUP AC Inf. Bull. 40, 23 (1971)

1971: S IUPAC Inf. Bull. 42/43, 8 (1972)

RA Comptes Rendus XXVI Conf., p 247 (1972)

TR Comptes Rendus XXVI Conf., p 225 (1972)

1972: $\quad$ (no meeting)

1973: $\quad$ S Comptes Rendus XXVII Conf., Part B, p 250 (1974)

RA Comptes Rendus XXVII Conf., Part B, p 303 (1974)

TR Comptes Rendus XXVII Conf., Part B, p 253 (1974).

49 H. Egan, Fd. Cosmet. Toxicol. 9, 81 (1971).

50 N. A. Smart, A. R. C. Hill and P. A. Roughan, J.A.O.A.C. 57,153 (1974).

51 C. A. Edwards (Ed.), Environmental Pollution by Pesticides, Plenum Press; London (1973).

52 C. A. Edwards, in C. A. Edwards (Ed.), Environmental Pollution by Pesticides, p 409. Plenum Press; London (1973).

53 R. Engst and R. Knoll, Nahrung, 17, 837 (1973).

54 H. Hellmann, Dtsch. Gewässerkundl. Mitt. 17, 47 (1973).

55 K. Schmidt. Gas- Wasserfach Wasser/Abwasser, 115, 72 (1974).

56 G. A. Wheatley, in C. A. Edwards (Ed.), Environmental Pollution by Pesticides, p. 365. Plenum Press; London (1973).

57 A. J. Murray and J. P. Riley, Nature, 242, 37-38 (1973).

58 E. M. Mrak, 3rd Int. Symp. on Chemical and Toxicological Aspects of Environmental Quality, Tokyo (Nov. 1973).

59 Australian Delegation, 'Collaborative study of analysis of malathion residues in wheat'. Room Document prepared for the 7th Session of the Codex Committee on Pesticide Residues (Feb. 1974).

60 E. F. McFarren, R. J. Lishka and J. H. Parker, Anal. Chem. 42, 358 (1970).

61 T. J. Farrell, Anal. Chem. 43, 156 (1971).

${ }^{62}$ L. D. Sawyer, J.A.O.A.C. 56, 1015 (1973).

63 H. Hadorn and K. Zürcher, Dtsch. Lebensm.-Rdsch. 69, 213 (1973).

64 J. H. A. Ruzicka and D. C. Abbott, Talanta, 20, 1261 (1973).

65 J. H. Ruzicka, in C. A. Edwards (Ed.), Environmental Pollution by Pesticides, p 11. Plenum Press; London (1973).

66 J. Sherma, C.R.C. Crit. Rev. Anal. Chem. 3, 299 (1973).

${ }^{67}$ S. G. Gorbach, S. Winkler and E. Gaudernack, Z. Anal. Chem. 267, 173 (1973).

68 Z. Masud, V. Bátora and J. Kovačičová, Pestic. Sci. 4, 131 (1973).

69 K. R. Griffitt and J. C. Craun, J.A.O.A.C. 57, 168 (1974).

70 J. J. Kirkland, J. Agric. Fd. Chem. 21, 171 (1973).

71 J. H. Knox, Proc. Soc. Anal. Chem. 10, 217 (1973).

72 H. M. McNair, Chromatographia, 7, 161 (1974).

73 R. E. Lovins, S. R. Ellis, G. D. Tolbert and C. R. McKinney, Anal. Chem. 45, 1553 (1973). 


\section{PROBLEMS AND APSECTS OF PRESENT-DAY RESIDUE ANALYSIS}

74 H.-Ch. Curtius, J. A. Völlmin and K. Baerlocher, Anal. Chem. 45, 1107 (1973).

75 J. Pflugmacher and W. Ebing, Z. Anal. Chem. 263, 120 (1973).

76 G. Voss, Methode S6 in Deutsche Forschungsgemeinschaft. Rückstandsanalytik von Pflanzenschutzmitteln, 3. Lief. Verl. Chemie; Weinheim/Bergstrasse (1974).

${ }^{77}$ K. Ramsteiner, W. D. Hörmann and D. O. Eberle, J.A.O.A.C. 57, 192 (1974).

78 J. H. A. Ruzicka, Pestic. Sci. 4, 417 (1973).

79 R. L. Tilden and C. H. Van Middelem, J. Agric. Fd. Chem. 18, 154 (1970).

80 L. I. Butler and L. M. McDonough, J.A.O.A.C. 53, 495 (1970).

81 E. R. Holden, J.A.O.A.C. 56, 713 (1973).

82 J. H. Caro, D. E. Glotfelty, H. P. Freeman and A. W. Taylor, J.A.O.A.C. 56, 1319 (1973).

83 E. Möllhoff, Bayer AG, Pflanzenschutz, Anwendungstechnik, Biologische Forschung, Institut für Rückstandsanalytik, Leverkusen, unpublished (1973).

84 G. Dräger, Bayer AG, Pflanzenschutz, Anwendungstechnik, Biologische Forschung, Institut für Rückstandsanalytik, Leverkusen, unpublished (1973).

85 H. A. Moye, J. Agric. Fd. Chem. 19, 452 (1971).

86 E. Möllhoff, Bayer AG, Pflanzenschutz, Anwendungstechnik, Biologische Forschung, Institut für Rückstandsanalytik, Leverkusen, Report RA-139 (March 1974).

87 J. P. Rouchaud and J. R. Decallonne, J. Agric. Fd. Chem. 22, 259 (1974).

88 J. Cox, L. Donegan and J. A. Pinegar, Pestic. Sci. 5, 135 (1974).

89 E. R. White, E. A. Bose, J. M. Ogawa, B. T. Manji and W. W. Kilgore, J. Agric. Fd Chem. 21, 616 (1973).

90 F. J. Baude, J. A. Gardiner and J. C. Y. Han, J. Agric. Fd Chem. 21, 1084 (1973).

91 H. L. Pease and R. F. Holt, J.A.O.A.C. 54, 1399 (1971).

92 N. Aharonson, N. and A. Ben-Aziz, J.A.O.A.C. 56, 1330 (1973).

93 J. F. Lawrence and R. W. Frei, J. Chromatog. 98, 253 (1974).

94 R. E. Duggan and M. B. Duggan, in C. A. Edwards (Ed.), Environmental Pollution by Pesticides, $\mathrm{p}$ 334. Plenum Press; London (1973).

95 H. Egan, in F. Coulston and F. Korte (Eds.), Environmental Quality and Safety, Vol. II, p 78. Thieme/Academic Press; Stuttgart/New York (1973).

96 D. G. Finlayson and H. R. MacCarthy, in C. A. Edwards (Ed.), Environmental Pollution by Pesticides, p 57. Plenum Press; London (1973).

97 Codex Committee on Pesticide Residues, 7th Session, CX/PR 74/2 (Aug. 1973).

98 WHO Secretariat, Codex Committee on Pesticide Residues, 7th Session, CX/PR/74/8 (Feb. 1974).

99 R. S. Adams, Jr., Residue Rev. 47, 1 (1973).

100 C. A. Edwards, Chem. Ind. 190 (1974).

101 J. Robinson, in C. A. Edwards (Ed.), Environmental Pollution by Pesticides, p 459. Plenum Press; London (1973).

102 M. C. Bowman, M. Beroza and K. R. Hill, J.A.O.A.C. 54, 346 (1971).

103 Ch.-sh. Feung, R. O. Mumma and R. H. Hamilton, J. Agric. Fd Chem. 22, 307 (1974).

104 R. L. Metcalf, Outlook Agric. 7, 55 (1972).

105 J. R. Sanborn and Ch.-Ch. Yu, Bull. Environ. Contam. Toxicol. 10, 340 (1973).

106 R. L. Metcalf, in W. J. Hayes, Jr. (Ed.), Essays in Toxicology, Vol. 5, p. 17. Academic Press; New York (1974).

107 Code of Federal Regulations, USA, 1971, para. 120.34; see also (R. Duggan), Pestic. Chemical News, July 11, 9 (1973).

108 W. Weinmann and A. Röpsch, Unterlagen zum Rückstandsverhalten eines Pflanzenschutzmittels im Rahmen des Zulassungsverfahrens, Merkblatt Nr. 35. Biologische Bundesanstalt für Land- und Forstwirtschaft; Braunschweig (Febr. 1973). 